\title{
Systematic review of accuracy of prenatal diagnosis for abnormal chromosome diseases by microarray technology
}

\author{
H.B. Xu, H. Yang, G. Liu and H. Chen \\ Department of Obstetrics and Gynecology, \\ The First Affiliated Hospital of Chongqing Medical University, \\ Chongqing, China \\ Corresponding author: H.B. Xu \\ E-mail: xhbyhr2008@sina.com
}

Genet. Mol. Res. 13 (4): 9115-9121 (2014)

Received July 22, 2013

Accepted December 6, 2013

Published October 31, 2014

DOI http://dx.doi.org/10.4238/2014.October.31.27

\begin{abstract}
The accuracy of prenatal diagnosis for abnormal chromosome diseases by chromosome microarray technology and karyotyping were compared. A literature search was carried out in the MEDLINE database with the keywords "chromosome" and "karyotype" and "genetic testing" and "prenatal diagnosis" and "oligonucleotide array sequence". The studies obtained were filtered by using the QUADAS tool, and studies conforming to the quality standard were fully analyzed. There was one paper conforming to the QUADAS standards including 4406 gravidas with adaptability syndromes of prenatal diagnosis including elderly parturient women, abnormal structure by type-B ultrasound, and other abnormalities. Microarray technology yielded successful diagnoses in 4340 cases $(98.8 \%$ ), and there was no need for tissue culture in $87.9 \%$ of the samples. All aneuploids and non-parallel translocations in 4282 cases of non-chimera identified by karyotyping could be detected using microarray analysis technology, whereas parallel translocations and fetal triploids could not be detected by microarray analysis technology. In the samples with normal karyotyping results, type-B ultrasound showed that
\end{abstract}


$6 \%$ of chromosomal deficiencies or chromosome duplications could be detected by microarray technology, and the same abnormal chromosomes were detected in $1.7 \%$ of elderly parturient women and samples with positive serology screening results. In the prenatal diagnosis test, compared with karyotyping, microarray technology could identify the extra cell genetic information with clinical significance, aneuploids, and non-parallel translocations; however, its disadvantage is that it could not identify parallel translocations and triploids.

Key words: Prenatal diagnosis; Abnormal chromosome diseases; Microarray

\section{INTRODUCTION}

As chromosome microarray analysis technology has developed, it has gradually become an important instrument for diagnosing abnormal chromosome structure and child hypoevolutism (Geifman-Holtzman and Ober, 2008). The aim of this study was to evaluate the accuracy and effect of microarray technology for routine prenatal diagnosis and additional fields relative to karyotyping. In this study, the accuracy, effect, and advantages of microarray technology compared to karyotyping were systematically evaluated by analyzing the relevant literature conducting comparative analysis on the two prenatal diagnosis techniques so as to provide medical evidence-based data for clinical research and large-scale applications in the near future.

\section{MATERIAL AND METHODS}

\section{Searching strategy}

The literature search was conducted in the MEDLINE database with the time period set from 1997 to 2013 using the following key words: chromosome and karyotype and genetic testing and prenatal diagnosis and oligonucleotide array sequence. The language was set to English and Chinese.

\section{Selection criteria}

The following criteria were used to select the literature included in the present analysis: 1) the research objective was to determine the accuracy and feasibility of microarray technology for prenatal diagnosis; 2) the accuracy determining process was compared to the traditional golden standard of karyotyping.

\section{Literature selection}

Two groups of independent experts judged the literature suitability based on the selection criteria by reading titles and abstracts. Studies consistent with the criteria were directly selected for this study, while those inconsistent were further evaluated by reading the full paper. In cases where the same data was published several times, only the most recent publication was selected for this analysis. 


\section{Data collection}

All studies selected for inclusion in the analysis must have included an accuracy analysis on non-invasive diagnosis and a simultaneous comparison analysis of the traditional karyotyping method. The sensitivity and specificity, along with $95 \%$ confidence intervals, of the non-invasive method were estimated from all data obtained from the literature selected.

\section{RESULTS}

\section{Literature selection}

The literature selection process is shown in Figure 1. There were 118 studies obtained from the key word search. After screening titles and abstracts, 8 studies related to microarray prenatal diagnosis were obtained and selected for further screening by reading the full text (Lim et al., 2010; Chiu et al., 2010; Papoulidis et al., 2012; Stumm et al., 2012; Talkowski et al., 2012; Schmid et al., 2013; Simpson, 2013; Vaiopoulos et al., 2013). Among these, 2 studies were disease case reports and 5 investigated microarray techniques for different fields but did not judge noninvasive prenatal accuracy at a large scale; therefore, these studies were excluded. One study was excluded since it did not include a control for the golden standard (Table 1). Finally, the one remaining study was selected for this analysis.

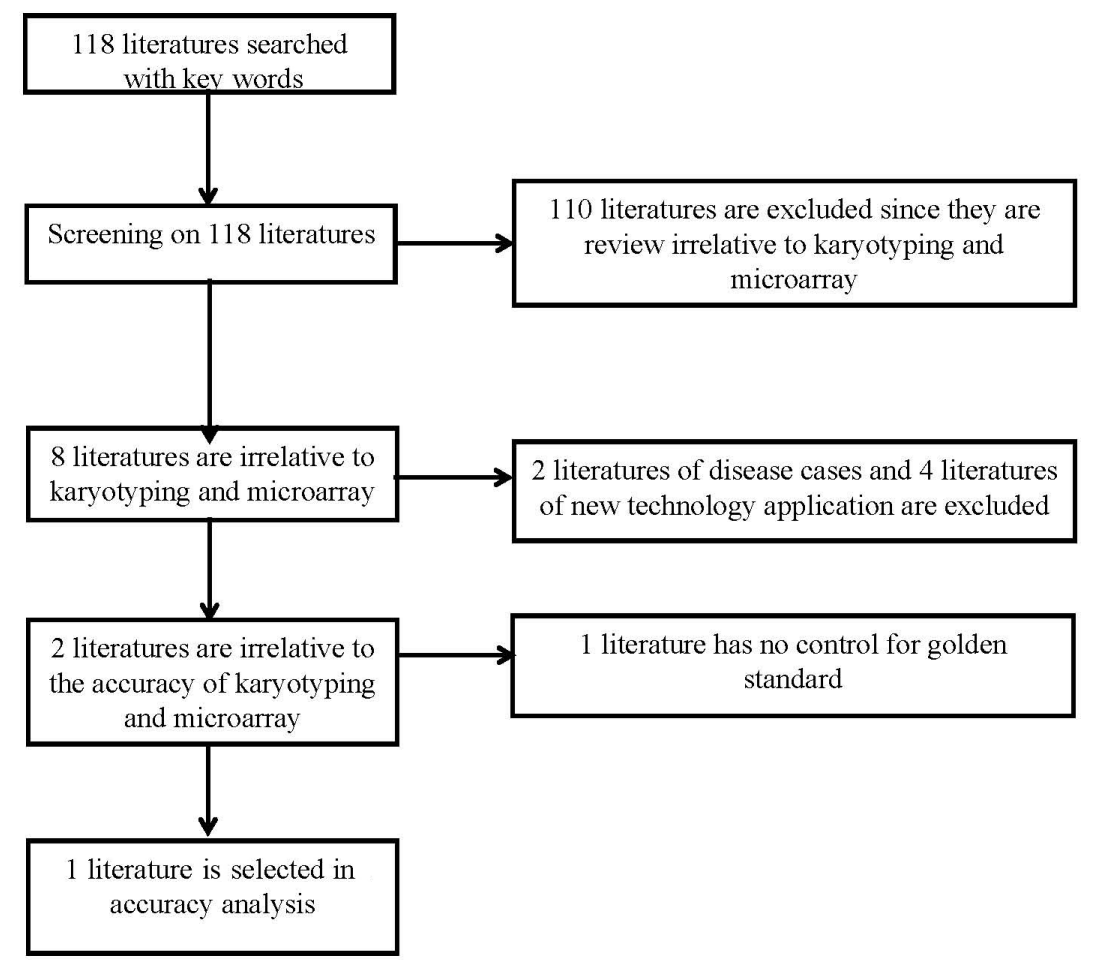

Figure 1. Literature selection process. 


\section{Table 1. Literature excluded reasons.}

\begin{tabular}{|c|c|c|}
\hline References & Titles & Excluded reasons \\
\hline Talkowski et al., 2012 & $\begin{array}{l}\text { Clinical diagnosis by whole-genome sequencing of } \\
\text { a prenatal sample }\end{array}$ & $\begin{array}{l}\text { One disease case report about prenatal diagnosis of } \\
\text { genome sequencing }\end{array}$ \\
\hline Chen et al., 2012 & $\begin{array}{l}\text { Mosaic ring chromosome } 21 \text {, monosomy } 21 \text {, and } \\
\text { isodicentric ring chromosome } 21 \text { : prenatal diagnosis, } \\
\text { molecular cytogenetic characterization, and association } \\
\text { with } 2-\mathrm{Mb} \text { deletion of } 21 \mathrm{q} 21.1-\mathrm{q} 21.2 \text { and } 5-\mathrm{Mb} \\
\text { deletion of } 21 \mathrm{q} 22.3\end{array}$ & $\begin{array}{l}\text { One disease case report on prenatal diagnosis } \\
\text { chimera } \mathrm{r}(21)\end{array}$ \\
\hline Schmid et al., 2012 & $\begin{array}{l}\text { Prenatal genetic diagnosis using microarray analysis in } \\
\text { fetuses with congenital heart defects }\end{array}$ & $\begin{array}{l}\text { Comparison between microarray and traditional } \\
\text { cell genetic method for prenatal diagnosis of } \\
\text { submicroscopic chromosome aberration }\end{array}$ \\
\hline Yan et al., 2011 & $\begin{array}{l}\text { Rapid screening for chromosomal aneuploidies } \\
\text { using array-MLPA }\end{array}$ & $\begin{array}{l}\text { Potential clinical application value of multiple } \\
\text { ligation-dependent probe amplification for fast } \\
\text { screening on abnomal chromosome }\end{array}$ \\
\hline Savage et al., 2011 & $\begin{array}{l}\text { Evolving applications of microarray analysis in } \\
\text { prenatal diagnosis }\end{array}$ & $\begin{array}{l}\text { Brief introduction on gene microarray including its } \\
\text { advantages and limitation but without comparison } \\
\text { with karyotyping }\end{array}$ \\
\hline Darilek et al., 2008 & $\begin{array}{l}\text { Pre- and postnatal genetic testing by array-comparative } \\
\text { genomic hybridization: genetic counseling perspectives }\end{array}$ & $\begin{array}{l}\text { Disease cases comparison between prenatal and } \\
\text { postpartum from the point of genetic consulting }\end{array}$ \\
\hline Larrabee et al., 2004 & $\begin{array}{l}\text { Microarray analysis of cell-free fetal DNA in } \\
\text { amniotic fluid: a prenatal molecular karyotype }\end{array}$ & $\begin{array}{l}\text { Microarray on no cell free fetal DNA in amniotic } \\
\text { fluid, a prenatal molecular karyotyping without } \\
\text { comparison with golden standard }\end{array}$ \\
\hline
\end{tabular}

\section{Data analysis}

As shown in Table 2, microarray analysis could detect abnormal heterosome, trisomy 21 , trisomy 18 , and trisomy 13 as well as other chromosome abnormalities and non-parallel translocations detected by karyotyping, but only karyotyping, and not microarray, could detect triploidy and parallel translocations.

Table 2. Detecting rate of abnormal chromosome detected by karyotyping and microarray.

\begin{tabular}{|c|c|c|c|c|}
\hline \multirow[t]{2}{*}{ Abnormality } & \multirow[t]{2}{*}{ Detected on karyotyping [N, (\%)] } & \multicolumn{3}{|c|}{ Detected on microarry } \\
\hline & & $\begin{array}{c}\text { Total } \\
{[\mathrm{N},(\%)]}\end{array}$ & $\begin{array}{l}\text { Full complement } \\
(\mathrm{N})\end{array}$ & $\begin{array}{l}\text { Mosaic complement } \\
(\mathrm{N})\end{array}$ \\
\hline $\begin{array}{l}\text { Any autosomal or sex-chromosome } \\
\text { abnormality }\end{array}$ & $374(8.7)$ & $374(100)$ & 366 & 8 \\
\hline Any common autosomal trisomy & $317(7.4)$ & $317(100)$ & 312 & 5 \\
\hline Trisomy 21 & 188 & $188(100)$ & 185 & 3 \\
\hline Trisomy 18 & 93 & $93(100)$ & 91 & 2 \\
\hline Trisomy 13 & 36 & $36(100)$ & 36 & 0 \\
\hline Other autosomal trisomy & $4(0.1)$ & $4(100)$ & 4 & 0 \\
\hline Any sex-chromosome aneuploidy & $57(1.3)$ & $57(100)$ & 54 & 3 \\
\hline $45, X$ & 39 & $39(100)$ & 36 & 3 \\
\hline 47, XXX; 47, XXY; 47, XYY & 18 & $18(100)$ & 18 & 0 \\
\hline Structural rearrangement & $65(1.5)$ & & & \\
\hline Balanced & 40 & 0 & 0 & 0 \\
\hline Unbalanced & 22 & $22(100)$ & 21 & 1 \\
\hline Marker & 3 & $2(66.7)$ & 2 & 0 \\
\hline Triploidy & $17(0.4)$ & 0 & 0 & 0 \\
\hline
\end{tabular}

As shown in Table 3, with respect to abnormalities that appeared normal by karyotyping, microarray application could improve the identification rate for detecting chromosome micro-deficiencies and micro-amplifications, and could also explain more clinical features at the chromosome level to facilitate the clinical diagnosis. 
Table 3. Rates of micro-deficiency and micro-amplification explained by microarray as for the actual abnormality but showing normal by karyotyping.

\begin{tabular}{|c|c|c|c|c|c|c|}
\hline \multirow[t]{2}{*}{ Indication for prenatal diagnosis } & \multirow{2}{*}{$\begin{array}{l}\text { Nomal } \\
\text { karyotype } \\
\text { (N) }\end{array}$} & \multirow{2}{*}{$\begin{array}{l}\text { Common } \\
\text { benign } \\
{[\mathrm{N},(\%)]}\end{array}$} & \multirow{2}{*}{$\begin{array}{c}\text { Pathogenic } \\
(\mathrm{N},(\%)]\end{array}$} & \multicolumn{2}{|c|}{ Uncertain clinical significance (N-130) } & \multirow{2}{*}{$\begin{array}{c}\text { Total known palthogenic } \\
\text { and potential for clinical } \\
\text { significance } \\
{[\mathrm{N},(\%)][95 \% \mathrm{CI}]}\end{array}$} \\
\hline & & & & $\begin{array}{c}\text { Likely to be } \\
\text { benign }[\mathrm{N},(\%)]\end{array}$ & $\begin{array}{l}\text { Potential for clinical } \\
\text { significance }[\mathrm{N},(\%)]\end{array}$ & \\
\hline Array & 3822 & $1234(32.3)$ & $35(0.9)$ & $69(1.8)$ & $61(1.6)$ & $96(2.5)[2.1-3.1]$ \\
\hline Advanced maternal age & 1966 & $628(31.9)$ & $9(0.5)$ & $37(1.9)$ & $25(1.3)$ & $34(1.7)[1.2-2.4]$ \\
\hline Positive on Down's syndrome screening & g 729 & $247(33.9)$ & $3(0.4)$ & $13(1.8)$ & $9(1.2)$ & $12(1.6)[0.9-2.9]$ \\
\hline Anomaly on ultrasonograph & 755 & $247(32.7)$ & $21(2.8)$ & $16(2.1)$ & $24(3.2)$ & $45(6.0)[4.5-7.9]$ \\
\hline Others & 372 & $112(30.1)$ & $2(0.5)$ & $3(0.8)$ & $3(0.8)$ & $5(1.3)[0.6-3.1]$ \\
\hline
\end{tabular}

\section{DISCUSSION}

In this study, the microarray effect on common prenatal diagnosis for aneuploidy was found to be equivalent to the current standard of chromosome karyotyping. In $1.7 \%$ of cases with prenatal diagnosis syndrome (elderly parturient women and positive aneuploid screening results), microarray provided additional relevant clinical information. In $6.0 \%$ of cases with abnormal type-B ultrasound results, microarray provided relevant clinical information. These results indicated that microarray is an advantageous test standard for prenatal screening; however, microarray and chromosome karyotyping analysis can detect uncertain mutations with clinical significance, which brings about challenges for genetic consultation and induces anxiety (Qu et al., 2013).

A microarray design was used in the study analyzed herein to detect characteristic micro-deficiencies and duplications to a maximum degree, and also contained oligonucleotide regions distributed in the genome to detect additional chromosomal imbalances. Of all normal cases analyzed by karyotyping, 3.4\% (130/3822) were further analyzed by microarray owing to uncertain results. Of these 130 cases, confirmed diagnoses were difficult in 94 (72.3\%) cases. Thus, expert reviews for clinical correlations are necessary.

The results obtained from uncultured samples were selected a priori in this study in order to avoid additional time and instruments for cell and tissue culturing. However, based on traditional genetic analysis and placental chimera experiments limited to chorion samples, different results will be obtained by evaluating direct samples of cytotrophoblasts (non-cultured) and classically cultured samples originating from the villous stroma core. Microarray analysis on non-cultured samples overcomes the genome contents of these 2 cell lines. Although the preliminary data showed that the microarray analysis results appear to be reliable between paired cultured cells and non-cultured cells, further evaluations are necessary due to the limited sample size.

After about 12 weeks of pregnancy, abnormal triploid cases are apparent by ultrasound, which leads to further evaluation by chromosome karyotyping; however, these abnormalities may not appear in pregnancies less than 12 weeks along. Microarray analysis includes single nucleotide polymorphism (SNP) probes to identify triploids with genotype data (Liu et al., 2012), but this information was not included in the research design.

Genotype data of SNP probes from the Affymetrix Company were not used in the microarray analysis investigated here, since this study was published before clinical applications 
of SNP probes became standard practice. However, since this study was published, it was confirmed that triploids could be identified by SNP data analysis. Therefore, we suggest that prenatal examinations should include SNP probe data analysis for more reliable triploid testing.

It is important to evaluate the incremental information degree required for effective prenatal examinations, and how to best introduce such information to clinical settings. We here found that microarray could detect abnormal heterosomes, trisomy 21 , trisomy 18 , and trisomy 13, as well as other chromosome abnormalities and non-parallel translocations that were detected by karyotyping, but only karyotyping could detect triploidy and parallel translocations, Microarray could improve the identification rate for detecting chromosome microdeficiencies and micro-amplification, decrease the omission rate caused by an insufficient identification rate of karyotyping, and explain more clinical features at the chromosome level.

When maternal blood samples are used for fetal genome sequencing, microarray analysis may be beneficial. Once this technology becomes clinically available, its application should be successful.

\section{ACKNOWLEDGMENTS}

Research supported by the National Natural Science Foundation of China (\#21075141), the Funding of National Key Clinical Department in China, and the National Key Clinical Specialist.

\section{REFERENCES}

Chen CP, Lin YH, Chou SY, Su YN, et al. (2012). Mosaic ring chromosome 21, monosomy 21, and isodicentric ring chromosome 21: prenatal diagnosis, molecular cytogenetic characterization, and association with 2-Mb deletion of 21q21.1-q21.2 and 5-Mb deletion of 21q22.3. Taiwan. J. Obstet. Gynecol. 51: 71-76.

Chiu RW, Sun H, Akolekar R, Clouser C, et al. (2010). Maternal plasma DNA analysis with massively parallel sequencing by ligation for noninvasive prenatal diagnosis of trisomy 21. Clin. Chem. 56: 459-463.

Darilek S, Ward P, Pursley A, Plunkett K, et al. (2008). Pre- and postnatal genetic testing by array-comparative genomic hybridization: genetic counseling perspectives. Genet. Med. 10: 13-18.

Geifman-Holtzman O and Ober BJ (2008). Prenatal diagnosis: update on invasive versus noninvasive fetal diagnostic testing from maternal blood. Expert. Rev. Mol. Diagn. 8: 727-751.

Larrabee PB, Johnson KL, Pestova E, Lucas M, et al. (2004). Microarray analysis of cell-free fetal DNA in amniotic fluid: a prenatal molecular karyotype. Am. J. Hum. Genet. 75: 485-491.

Lim AS, Lim TH, Hess MM, Kee SK, et al. (2010). Rapid aneuploidy screening with fluorescence in-situ hybridisation: is it a sufficiently robust stand-alone test for prenatal diagnosis? Hong Kong Med. J. 16: 427-433.

Liu HY, Wu D, Li H, Guo SK, et al. (2012). Significance of detecting free DNA from maternal plasma for the diagnosis of fetal chromosomal aneuploidies. Zhonghua Yi Xue Yi Chuan Xue Za Zhi 29: 435-438.

Papoulidis I, Siomou E, Sotiriadis A, Efstathiou G, et al. (2012). Dual testing with QF-PCR and karyotype analysis for prenatal diagnosis of chromosomal abnormalities. Evaluation of 13,500 cases with consideration of using QF-PCR as a stand-alone test according to referral indications. Prenat. Diagn. 32: 680-685.

Qu X, Randhawa G, Friedman C, O'Hara-Larrivee S, et al. (2013). A novel four-color fluorescence in situ hybridization assay for the detection of TMPRSS2 and ERG rearrangements in prostate cancer. Cancer Genet. 206: 1-11.

Savage MS, Mourad MJ and Wapner RJ (2011). Evolving applications of microarray analysis in prenatal diagnosis. Curr. Opin. Obstet. Gynecol. 23: 103-108.

Schmid M, Stary S, Blaicher W, Gollinger M, et al. (2012). Prenatal genetic diagnosis using microarray analysis in fetuses with congenital heart defects. Prenat. Diagn. 32: 376-382.

Schmid M, Stary S, Springer S, Bettelheim D, et al. (2013). Prenatal microarray analysis as second-tier diagnostic test: single-center prospective study. Ultrasound Obstet. Gynecol. 41: 267-273.

Simpson JL (2013). Cell-free fetal DNA and maternal serum analytes for monitoring embryonic and fetal status. Fertil. 
Steril. 99: 1124-1134.

Stumm M, Entezami M, Trunk N, Beck M, et al. (2012). Noninvasive prenatal detection of chromosomal aneuploidies using different next generation sequencing strategies and algorithms. Prenat. Diagn. 32: 569-577.

Talkowski ME, Ordulu Z, Pillalamarri V, Benson CB, et al. (2012). Clinical diagnosis by whole-genome sequencing of a prenatal sample. N. Engl. J. Med. 367: 2226-2232.

Vaiopoulos AG, Athanasoula KC, Papantoniou N and Kolialexi A (2013). Review: advances in non-invasive prenatal diagnosis. In Vivo 27: 165-170.

Yan JB, Xu M, Xiong C, Zhou DW, et al. (2011). Rapid screening for chromosomal aneuploidies using array-MLPA. BMC Med. Genet. 12: 68. 